\title{
Optimized Sliding Mode Control of Three-Phase Four-Switch Inverter BLDC Motor Drive Using LFD Algorithm
}

\author{
Quasy S. Kadhim*1, Abbas H. Abbas ${ }^{1}$, Mohammed M. Ezzaldean ${ }^{2}$ \\ ${ }^{1}$ Electrical Engineering Department, University of Basrah, Iraq \\ ${ }^{2}$ Department of Electrical Engineering, University of Technology, Iraq
}

\author{
Correspondence \\ * Quasy S. Kadhim, \\ Electrical Engineering Department, \\ University of Basrah, Basrah, Iraq. \\ Email: qusay.eifaan@uobabylon.edu.iq
}

\begin{abstract}
This paper presents a low-cost Brushless DC (BLDC) motor drive system with fewer switches. BLDC motors are widely utilized in variable speed drives and industrial applications due to their high efficiency, high power factor, high torque, low maintenance, and ease of control. The proposed control strategy for robust speed control is dependent on two feedback signals which are speed sensor loop which is regulated by Sliding Mode Controller (SMC) and current sensor loop which is regulated by Proportional-Integral (PI) for boosting the drive system adaptability. In this work, the BLDC motor is driven by a four-switch three-phase inverter emulating a three-phase six switch inverter, to reduce switching losses with a low complex control strategy. In order to reach a robust performance of the proposed control strategy, the Lévy Flight Distribution (LFD) technique is used to tune the gains of PI and SMC parameters. The Integral Time Absolute Error (ITAE) is used as a fitness function. The simulation results show the SMC with LFD technique has superiority over conventional SMC and optimization PI controller in terms of fast-tracking to the desired value, reduction speed error to the zero value, and low overshoot under sudden change conditions.
\end{abstract}

KEYWORDS: Four Switch Inverter, Sliding Mode Speed Controller, Low Cost BLDC Motor Drive, LFD Algorithm, PI Controller.

\section{INTRODUCTION}

BLDC motor is a combining the advantages of DC motor with $\mathrm{AC}$ motor to produce a new special motor and it responds to the rapid development of power electronic technology, control theory, and permanent magnetic materials [1]. BLDC motors are widely utilized in variable speed drives and industrial applications due to their high efficiency, high power factor, high torque, low maintenance, and ease of control [2].

A BLDC motor produces to provide continuous torque by combining trapezoidal back EMF with square-wave currents [3]. A six-switch, three-phase inverter and three Hall-effect position sensors are used to give six commutation points for each electrical cycle in a traditional BLDC motor drive. In a fractional horsepower BLDC motor drive for household applications, cost minimization is critical.

In recent years, elimination of driving components such as power switches was achieved. As a result, efficient algorithms should be created to get the desired results. For a three-phase BLDC motor drive, a four-switch, three-phase inverter (FSTPI) topology was recently developed and implemented. The key features of this topology are the reduction in the number of power switches, dc power supply, switching driver circuits, losses, and total price [4]. Conventional control approaches, on the other hand, are ineffective for current regulation in the four-switch architecture. Based on the independent control of the phases' current, [4] devised a new and effective current control strategy to achieve 120 rectangular currents. In order to maintain the BLDCM is stable under various condition such as variable loads, and parameters change, the control approach must be adaptable, resilient, accurate, and easy to apply $[5,6]$. Linear and nonlinear feedback controls are the two types of feedback controls available. The linear controller has been demonstrated to be an effective and simple control architecture in a study of linear control techniques such as Proportional-Integral-Derivative (PID) control in [7]. Nonetheless, traditional linear control has a number of significant merits. The linear control has several disadvantages, including the fact that it is only useful for slow-speed systems and is susceptible to uncertainties [7]. In light of these flaws, nonlinear controls such as model predictive control (MPC) [8], sliding mode control (SMC) [9] have been developed to 
achieve high tracking control in the presence of uncertainties for high-speed applications. SMC is well-known as a basic control method that is insensitive to matching uncertainty among various nonlinear control strategies. The chattering phenomena, robustness degradation during the reaching phase, and susceptibility to unmatched uncertainty are the most often mentioned issues with the traditional SMC.

Advanced control techniques such as adaptive control, variable structure control, fuzzy control, and neural networks can be used to solve this challenge $[5,10,11]$. The inability to perform trajectory control in the presence of unexpected disruptions or big noises is one of the key issues with implementing self-tuning adaptive control approaches. This is because, in the case of rapid disturbances or huge sounds, the parameter estimator may produce incorrect findings [6]. Although the variable structure controller is simple, it is challenging to put into practice. This is due to the risk of a sudden shift in the control signal, which could disrupt system operation [11]. The ability of a neural-network-based motor control system to address the structure uncertainty and disturbance of the system is considerable, but it requires more computational power and data storage space [10]. Non-linear controllers based on fuzzy control theory are typically capable of conducting a variety of complicated non-linear control actions, even for uncertain non-linear systems [4-10]. Unlike traditional control design, an FLC does not necessitate accurate knowledge of the system model, such as the system transfer function's poles and zeroes [11]. Although a fuzzy-logic control system based on an expert knowledge database requires fewer calculations, it does not have enough capacity to handle the new rules [6]. In order to solve these issues, the sliding mode control (SMC) is used $[9,11]$.

SMC is a control system that can keep a system stable in a variety of models with different interference and system parameters. As a result, it's frequently employed in nonlinear models. SMC has a working area in the steady state phase, which allows it to maintain system performance when disturbances and parameter changes occur. SMC based on optimization algorithm is a new system that allows you to arrange the SMC sliding surface based on a best setting. This is done to improve the system's transient response over the previous SMC [12].

With the advancement of artificial intelligence control technology, numerous authors have been used intelligence algorithms for control of BLDCM, such as firefly Algorithm [12], genetic algorithm [13], fuzzy logic control [14], neural network [15], Sine-Cosine Algorithm (SCA) [16], Particle Swarm Optimization (PSO) [16], Moth Swarm Algorithm (MSA) [17], Bat algorithm [18], and bacterial Foraging algorithm [19] have increasingly been added to the traditional PID controller.

This paper presents a low cost optimized BLDC motor drive using three phase four switch inverter (TPFSI) emulating the traditional six switches inverter. In this study, to the authors' knowledge, a new meta-heuristic algorithm for solving engineering issues that presented by [20] is used for first time for speed control of BLDCM based on TPFSI for tuning the parameters of SMC which is called Lévy flight distribution (LFD). The proposed control is simple and robust.

\section{BLDC MOTOR MODELLING}

For designing the sliding mode control strategy and to analysis the dynamic response with characteristics of BLDC motor, the mathematical model with equivalent circuit is required. Fig. (1) show the equivalent circuit of BLD motor. The differential voltage equations according to the equivalent circuit can be deduced in equation (1) [1].

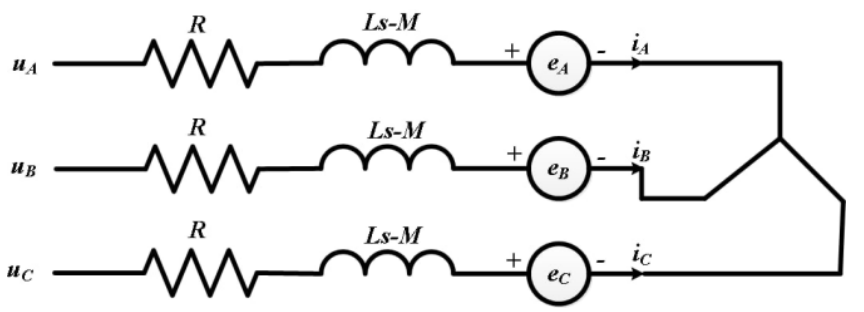

. Fig. 1: Equivalent circuit of the BLDC motor.

$$
\left.\begin{array}{l}
v_{a}=R_{a} i_{a}+L_{a} \frac{d i_{a}}{d t}+L_{a b} \frac{d i_{b}}{d t}+L_{c a} \frac{d i_{c}}{d t}+e_{a} \\
v_{b}=R_{b} i_{b}+L_{b} \frac{d i_{b}}{d t}+L_{b a} \frac{d i_{a}}{d t}+L_{b c} \frac{d i_{c}}{d t}+e_{b} \\
v_{c}=R_{c} i_{c}+L_{a} \frac{d i_{a}}{d t}+L_{a b} \frac{d i_{b}}{d t}+L_{c a} \frac{d i_{c}}{d t}+e_{c}
\end{array}\right\}
$$

"Where ,va, vb, vc are the stator phase voltages ia, ib, ic are stator phase currents ea, eb, ec are trapezoidal phase back EMF, $R_{a}, R_{b}, R_{c}$ are stator resistances $L_{c a}, L_{b c}, L_{c a}$ are the mutual inductances, and $L_{a}, L_{b}, L_{c}$ are self-inductance per phase".

We can have expressed the above equation in the matrix form as:

$\left[\begin{array}{l}v_{a} \\ v_{b} \\ v_{c}\end{array}\right]=\left[\begin{array}{ccc}R_{a} & 0 & 0 \\ 0 & R_{b} & 0 \\ 0 & 0 & R_{c}\end{array}\right]\left[\begin{array}{l}i_{a} \\ i_{b} \\ i_{c}\end{array}\right]+\frac{d}{d t}\left[\begin{array}{ccc}L_{a} & L_{a b} & L_{c a} \\ L_{b a} & L_{b} & L_{b c} \\ L_{c a} & L_{c b} & L_{c}\end{array}\right]\left[\begin{array}{c}i_{a} \\ i_{b} \\ i_{c}\end{array}\right]+\left[\begin{array}{l}e_{a} \\ e_{b} \\ e_{c}\end{array}\right]$

BLDC motors typically use a surface-mounted salient-pole rotor. The winding inductance will not change with time in this situation. Furthermore, because the three-phase stator windings are symmetrical, the self-inductances and mutual inductances will be equal, and we have:

$$
\begin{gathered}
i_{a}+i_{b}+i_{c}=0 \\
L_{a}=L_{b}=L_{c}=L_{s} \\
R_{a}=R_{c}=R_{c}=R \\
L_{a b}=L_{a c}=L_{b c}=L_{b a}=L_{c a}=L_{a b}=M
\end{gathered}
$$

Since, equation (2) can be rewritten as:

$$
\left[\begin{array}{l}
v_{a} \\
v_{b} \\
v_{c}
\end{array}\right]=\left[\begin{array}{ccc}
R & 0 & 0 \\
0 & R & 0 \\
0 & 0 & R
\end{array}\right]\left[\begin{array}{l}
i_{a} \\
i_{b} \\
i_{c}
\end{array}\right]+\frac{d}{d t}\left[\begin{array}{ccc}
L_{s} & M & M \\
M & L_{s} & M \\
M & M & L_{s}
\end{array}\right]\left[\begin{array}{l}
i_{a} \\
i_{b} \\
i_{c}
\end{array}\right]+\left[\begin{array}{c}
e_{a} \\
e_{b} \\
e_{c}
\end{array}\right]
$$

Where, $L=L_{s}-M$, and the phase voltage equations of a BLDC motor can thus be represented in matrix form as:

$$
\left[\begin{array}{l}
v_{a} \\
v_{b} \\
v_{c}
\end{array}\right]=\left[\begin{array}{ccc}
R & 0 & 0 \\
0 & R & 0 \\
0 & 0 & R
\end{array}\right]\left[\begin{array}{c}
i_{a} \\
i_{b} \\
i_{c}
\end{array}\right]+\frac{d}{d t}\left[\begin{array}{lll}
L & M & M \\
M & L & M \\
M & M & L
\end{array}\right]\left[\begin{array}{c}
i_{a} \\
i_{b} \\
i_{c}
\end{array}\right]+\left[\begin{array}{l}
e_{a} \\
e_{b} \\
e_{c}
\end{array}\right]
$$




$$
\left.\begin{array}{c}
e_{a}=K_{e} \omega_{r} F\left(\theta_{e}\right) \\
e_{a}=K_{e} \omega_{r} F\left(\theta_{e}-\frac{2 \pi}{3}\right) \\
e_{a}=K_{e} \omega_{r} F\left(\theta_{e}+\frac{2 \pi}{3}\right)
\end{array}\right\}
$$

Finally, the developed torque equation can be expressed as bellow:

$T_{e}=K_{\omega} \omega_{r} F\left(\theta_{e}\right) i_{a}+K_{\omega} \omega_{r} F\left(\theta_{e}-\frac{2 \pi}{3}\right) i_{b}+K_{\omega} \omega_{r} F\left(\theta_{e}+\right.$

$\left.\frac{2 \pi}{3}\right) i_{c}$

Or it can be depicted according to motion equation and we have:

$$
T_{e}=J \frac{d \omega_{r}}{d t}+B \omega_{r}+T_{l}
$$

Where the function $\mathrm{F}$ can be defined as:

$$
\left.F\left(\theta_{e}\right)=\begin{array}{c}
1 \text { if } 0 \leq \theta_{e}<\frac{2 \pi}{3} \\
1-\frac{6}{\pi}\left(\theta_{e}-\frac{2 \pi}{3}\right) \text { if } \frac{2 \pi}{3} \leq \theta_{e}<\pi \\
-1 \text { if } \pi \leq \theta_{e}<\frac{5 \pi}{3} \\
-1+\frac{6}{\pi}\left(\theta_{e}-\frac{5 \pi}{3}\right) \text { if } \frac{5 \pi}{3} \leq \theta_{e}<2 \pi
\end{array}\right\}
$$

The above equations that describing the model of BLDC motor are using in designing of SMC strategy for speed control of BLDC motor using TPFSI power topology.

\section{Four Switch Three Phase InVerter}

This section presented the principle operation and constraints of the three-phase four-switch (TPFS) which fed the BLDC motor as shown in Fig. (2). The TPFS has four power switches and two capacitors with equal value. The two phases of the BLDC motor are connected to the two legs of the TPFS inverter and the third phase is connected to the midpoint of two capacitors $\left(\mathrm{C}_{1}\right.$ and $\left.\mathrm{C}_{2}\right)$. The values of the two capacitors in this configuration are must be the same in order to spilt the DC source into half ( $\mathrm{Vdc} / 2)$. The Back Electromotive Force (BEF) should be trapezoidal in shape, with $120^{\circ}$ conductions and $60^{\circ}$ non-conducting sections, and quasi square wave currents are required to generate constant output torque, therefore correct rotor position is necessary by using robust controller. In order to investigate this objective, the three hall sensor signals can be used to gather this information. The four PWM signals are necessary to turn on the inverter's four switches.

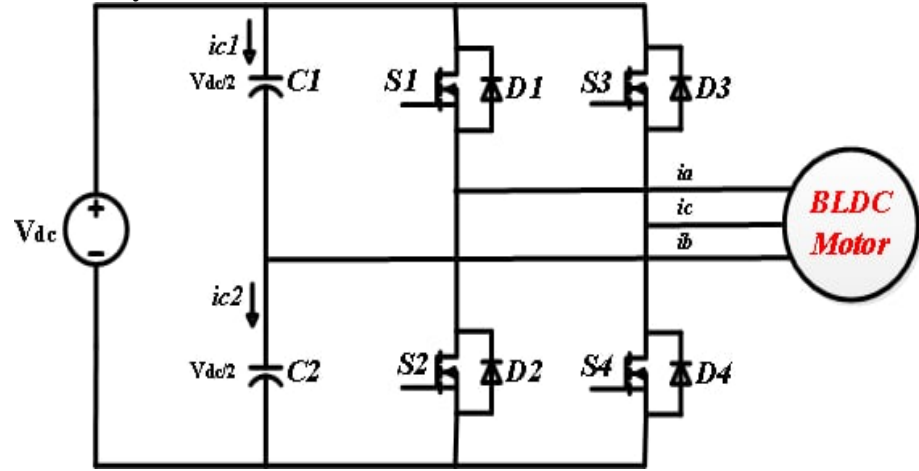

Fig. 2: configuration of four switch fed BLDC motor

To commutate the motor, the inverter generates trapezoidal back EMF waveforms and quasi square wave currents. Torque is generated as a result of the magnetic field generated by the stator coils interacts with the permanent magnets. The switching sequences for a four-switch inverter are shown in Table I. The link between hall sensor signals and phase voltages is shown in Table II.

TABLE I

SWITCH SEQUENCING FOR TPFS

\begin{tabular}{|c|c|c|c|c|}
\hline $\begin{array}{c}\text { Hall sensor } \\
\text { (h1,h2,h3) }\end{array}$ & modes & $\begin{array}{c}\text { Active } \\
\text { phases }\end{array}$ & $\begin{array}{c}\text { inactive } \\
\text { phases }\end{array}$ & Switching \\
\hline 010 & Mode 1 & C,B & A & $\mathrm{S}_{4}$ \\
\hline 110 & Mode 2 & A,B & C & $\mathrm{S}_{1}, \mathrm{~S}_{4}$ \\
\hline 100 & Mode 3 & A,C & B & $\mathrm{S}_{1}$ \\
\hline 101 & Mode 4 & B,C & A & $\mathrm{S}_{3}$ \\
\hline 001 & Mode 5 & B,A & C & $\mathrm{S}_{2}, \mathrm{~S}_{3}$ \\
\hline 011 & Mode 6 & C,A & B & $\mathrm{S}_{2}$ \\
\hline
\end{tabular}

TABLE II

SIGNALS OF HALL SENSOR AND PHASE VOLTAGES

\begin{tabular}{|c|c|c|c|c|c|}
\hline ha & hb & hc & Phase A & Phase B & Phase C \\
\hline 1 & 0 & 0 & $+\mathrm{V}_{\mathrm{dc}}$ & $-\mathrm{V}_{\mathrm{dc}}$ & $\mathrm{NC}$ \\
\hline 1 & 1 & 0 & $+\mathrm{V}_{\mathrm{dc}}$ & $\mathrm{NC}$ & $-\mathrm{V}_{\mathrm{dc}}$ \\
\hline 0 & 1 & 0 & $\mathrm{NC}$ & $+\mathrm{V}_{\mathrm{dc}}$ & $-\mathrm{V}_{\mathrm{dc}}$ \\
\hline 0 & 1 & 1 & $-\mathrm{V}_{\mathrm{dc}}$ & $+\mathrm{V}_{\mathrm{dc}}$ & $\mathrm{NC}$ \\
\hline 0 & 0 & 1 & $-\mathrm{V}_{\mathrm{dc}}$ & $\mathrm{NC}$ & $+\mathrm{V}_{\mathrm{dc}}$ \\
\hline 1 & 0 & 1 & $\mathrm{NC}$ & $-\mathrm{V}_{\mathrm{dc}}$ & $+\mathrm{V}_{\mathrm{dc}}$ \\
\hline
\end{tabular}

\section{CONTROL Strategy}

This paper presents a comparison between traditional technique and optimized SMC based on LFD algorithm. The tradition control strategies that considering in this paper are PI controller without optimized gains, PI controller with optimized gains and traditional SMC controller. To make a good comparison, the concept of PI and SMC are explained with modeling in the bellow sections:

\section{A. PI Controller}

Because adjustment of the parameters can be done with relation to the system's output characteristics, PI control is commonly employed in industrial control systems. The following is a general equation of the PI controller:

$$
u(t)=K_{p} e(t)+K_{i} \int e(t) d t
$$

Where $e(t)=\omega_{r}{ }^{*}-\omega_{r}$

An overshoot would be seen at the output when the controller parameters are set too high. Small parameter magnitudes, on the other hand, may result in steady state error or a long period to attain reference speed. For this reasons, the optimization algorithm is required to adjust the optimal parameters of PI controller to reach a better performance for any system under study.

\section{B. SMC Controller}

The first process to design the SMC is to form the sliding surface. In general, the equation mostly used for the sliding surface can be written as:

$$
\begin{aligned}
& \mathrm{s}(\mathrm{t})=C X_{1}+X_{2}=\mathrm{Ce}(\mathrm{t})+\dot{e}(t) \\
& \dot{s}(t)=C \dot{X}_{1}+\dot{X}_{2}=C \dot{e}(t)+\ddot{e}(t) \\
& \text { Where } e(t)=y^{*}-y
\end{aligned}
$$


It is shown that sliding surface is an action, which is related to tracking error, Any difference between reference and actual output. In here. $\mathrm{C}>0$ is performance parameter which guaranteed the stability of the system. on sliding surface $[9,11,22]$. The sliding function and its derivative over the sliding surface are both equal to zero $(\mathrm{s}(\mathrm{t}) 0$ and $\mathrm{s}(\mathrm{t})=0)$. The SMC's control signal law $\mathrm{u}(\mathrm{t})$ is made up of two parts: an equivalent control signal $\mathrm{u}_{\mathrm{eq}}(\mathrm{t})$ and a switching control signal $\mathrm{u}_{\mathrm{sw}}(\mathrm{t})$, both of which are determined using the equations below:

Where

$$
\begin{gathered}
u(t)=u_{e q}(t)+u_{s w}(t) \\
u_{s w}(t)=k \operatorname{sgn}(s)
\end{gathered}
$$

$$
\operatorname{sgn}(s(t))=\left\{\begin{array}{c}
+1, \text { if } s(\mathrm{t})>0 \\
0, \text { if } \mathrm{s}(\mathrm{t})=0 \\
-1, \text { if } \mathrm{s}(\mathrm{t})<0
\end{array}\right.
$$

$\operatorname{sgn}($.$) represents signum function, where \mathrm{k}$ is a positive design parameter that is chosen to be quite large to suppress system uncertainties and unexpected dynamics. While $s(t) 0$, the signal $\mathrm{u}_{\mathrm{sw}}(\mathrm{t})$ moves the system's states to the sliding surface. The switching control signal is turned off as it reaches the sliding surface. Despite the fact that the comparable control signal is continuous, the switching control signal is discontinuous due to the scenario [21-23].

The motion equation that describe in equation (11) can be rewritten as:

$$
J \frac{d \omega_{r}}{d t}=k_{t} u-B \omega_{r}-T_{l}
$$

the sliding surface can be written in terms of error as:

$$
s(\omega)=C e-\dot{e}
$$

Where the tracking error is equal to: $e(t)=\omega_{r}^{*}-\omega_{r}$

Assume the $s \dot{(\omega)}=0$, and we have:

$$
s \dot{(\omega)}=e=\dot{\omega}_{r}^{*}-\dot{\omega}_{r}=\dot{\omega}_{r}^{*}-\frac{k_{t}}{J} u+\frac{B}{J} \omega+\frac{1}{J} T_{l}=0
$$

The equivalent control is designed according to observer torque and it can be depicted as

$$
u_{e q}=\frac{1}{k_{t}}\left(J \dot{\omega}^{*}+B \omega+T_{l}\right)
$$

And, the switching control is depending on the sliding surface signal and it can be expressed as:

Finally, the actual control is

$$
u_{s w}=k \operatorname{sgn}(s)
$$

$$
u=u_{e q}+u_{s w}
$$

By substituting Eq. (22 and 23) into Eq. (24), the final form of actual control equation that depending in simulation is:

$$
u=\frac{1}{k_{t}}\left(J \dot{\omega}_{r}^{*}+B \omega+T_{l}\right)+k \operatorname{sgn}(s)
$$

Equation (25) is using for regulating the output speed of BLDC motor to achieve to the desired speed under various conditions.

\section{Proposed Control Structure}

The proposed control strategy that including two loops control which are speed control loop and current control loop are presented in Fig. (3). In this paper, the optimized SMC is used for speed controller and compared with optimized PI controller and traditional SMC to show the effectiveness in tracking the desired trajectory. While, the optimized PI controller is used to regulate the stator current of BLDCM. The parameters of SMC approach and the two PI controller is tuning by LFD algorithm in order to achieve excellent performance under non-uniform conditions.

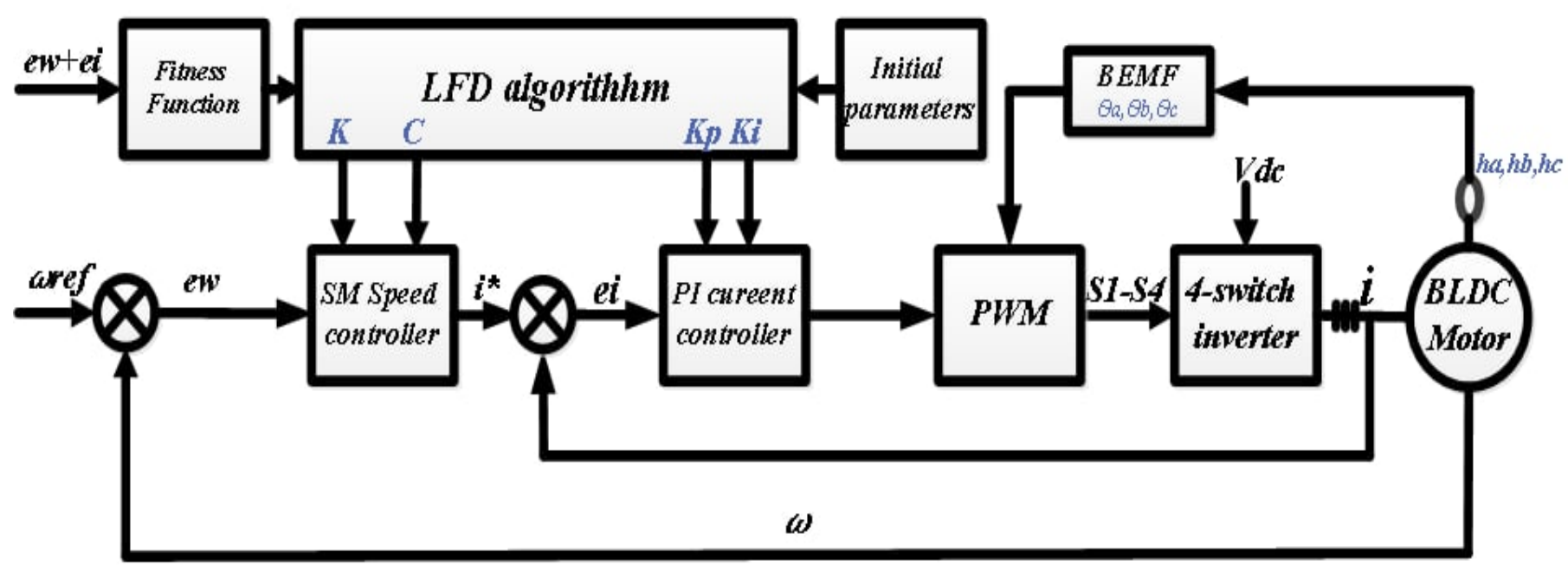

Fig. 3: The structure of a BLDC motor with proposed control approach. 


\section{LÉVY FLIGHT DISTRIBUTION (LFD)}

\section{A. Inspiration}

The suggested algorithm is primarily focused on the environment of wireless sensor networks combined with Lévy Flight (LF) motions [20]. As seen in Fig. 4, LF can be considered a random walk. The LF shown that in uncertain contexts, it can improve the efficiency of resource searches. In reality, numerous natural-inspired or physical-inspired occurrences in the environment can inspire LFs. The pathways of LF styles can be followed by natural animals such as spider monkeys, fruit flies, and humans. Furthermore, albatross foraging practices have been discovered as an inspiration phase for the LFs. Noise and cooling behaviors indicate the features of LFs under the correct conditions, and diffusion of fluorescent molecules might be considered a physically-inspired phenomenon for the inspiration of LFs. Furthermore, LFs are more efficient than Brownian random walks in exploring unknown big search areas. This efficiency is the primary justification for include LFs in the proposed optimization technique.

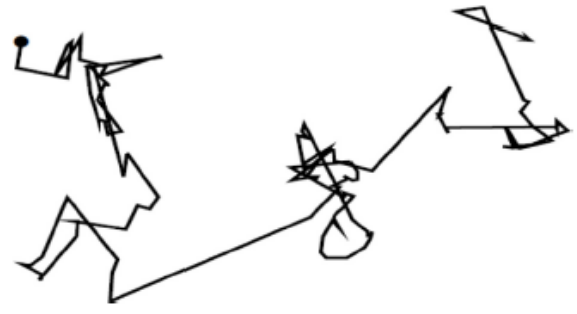

Fig. 4: Lévy flights of fifty sequential steps starting from the origin marked with a bold point [20].

\section{B. Mathematical model of LFD}

The environment of wireless sensor network is used for mathematical Modeling. Algorithm begins its mechanism by finding the Euclidean Distance (ED) between the nodes of each two neighboring sensor. After that, algorithm decides whether node be in its original location depending on ED or moving it to another position. Another location will be calculated using LFs model in which the new location will be in a place that closes to a node which has a low neighboring nodes or in a place that has no nodes in the search space to decrease the chances for overlapping occurring among sensor nodes.

For random walks generation, "it is ought to assign two characteristics: the walk length step following the selected Lévy distribution and the orientation that because it moves to the target location in the proposed algorithm, that may be derived from the symmetric distribution. Many procedures may determine the mentioned features, but the easiest and effective method is Mantegna algorithm for a stable and uniform distribution" [20].

With reference to Mantegna's algorithm, the step length $S$ is:

$$
S=\frac{U}{|V|^{1 / \beta}}
$$

Where $\beta$ is the index of Lévy distribution limited as $0<\beta \leq 2$, $\mathrm{U}$ and $\mathrm{V}$ are such that $U \sim N\left(0, \sigma_{u}^{2}\right), V \sim N\left(0, \sigma_{V}^{2}\right)$
The standard deviation $\sigma u$ and $\sigma v$ are:

$$
\sigma_{u}=\left\{\frac{\Gamma(1+\beta) * \sin (\pi \beta / 2)}{\Gamma[(1+\beta) / 2] * \beta * 2^{(\beta-1) / 2}}\right\}^{1 / \beta}, \sigma_{v}=1
$$

for an integer $z$ the Gamma function $\Gamma$ is:

$$
\Gamma(z)=\int_{0}^{\infty} t^{z-1} e^{-t} d t
$$

Euclidean distance $E D$ between the first two adjacent Agents (and $X J)$ positions:

$$
E D\left(X_{i}, X_{J}\right)=\sqrt{\left(X_{i}, X_{J}\right)^{2}++\left(y_{J}, Y_{i}\right)^{2}}
$$

$\mathrm{x}_{\mathrm{i}}, \mathrm{y}_{\mathrm{i}}$ is the $\mathrm{X}_{\mathrm{i}}$ position coordinate, $x_{J}, y_{J}$ is $x_{J}$ position coordinate. ED is compared with a specified threshold till the agents are terminated after a defined iterations number. If the distance resulted is less than threshold, the mechanism of algorithm begins by adjusting agents' positions using:

$$
X_{J}(t+1)=L e^{\prime} v y_{F l i g h t}\left(X_{J}(t), X_{\text {Leader }}, L B, U B\right)
$$

Where $\mathrm{t}$ is iterations index, the function Levy_Flight accomplish the Levy flights work in terms of the orientation a step length. LB and UB are the lowest and highest values in the search space $2 \mathrm{D}$ dimensions. $\mathrm{X}_{\text {Leader }}$ is the agent position which has neighbors of lowest number and will be used as direction of the LF. Eq. (30) moves $X_{J}$ agent towards the agent's position which has lowest number of neighbors.

$$
X_{J}(t+1)=L B+(U B-L B) \operatorname{rand}()
$$

Where the function rand ( ) is used to produce $\mathrm{R}$ random numbers in the $[0,1]$ uniform distribution. Eq. (31) introduce more opportunities for finding solutions of non-visited position in the search space and the suggested algorithm exploration phase increasing. Eq. (30) updates the $X_{J}$ position to a new area in the search space where no other agents are there.

$$
R=\operatorname{rand}(), C S V=0.5
$$

Where CSV is a scalar value for comparison with $\mathrm{R}$ in each update for the $\mathrm{X}_{\mathrm{J}}$ position. For updating the node $X_{J}$ position, $\mathrm{R}$ is checked on at every iteration in Eq. (32). If $\mathrm{R}$ is less than $\mathrm{CSV}$, execute Eq. (30). If not, execute Eq. (31) to give more chances to find the search space. Altering the solutions of algorithm increase it capability of exploration and improve its performance. The suggested algorithm updates the $\mathrm{X}_{\mathrm{i}}$ using:

$$
\begin{aligned}
& X_{i}(t+1)=T P+\alpha_{1} * T F_{\text {Neighbours }}+\operatorname{rand}() * \alpha_{2} * \\
& \left(T P+\alpha_{1} F_{\text {Neighbours }} / 2-X_{i}(t)\right) \\
& X_{i}^{\text {New }}(t+1)=\text { Le'vy_Flight }\left(X_{i}(t+1), T P, L B, U B\right)
\end{aligned}
$$

New $X_{i}$ is calculated by Eq. (33), while $X_{i}$ final position is get by Eq. (34). T P is the solution achieving the objective function best fitness value, that is named the target position. $\alpha 1$, $\alpha 2$ and $\alpha 3$ are random numbers, their values are such that $0<$ $\alpha 1, \alpha 2, \alpha 3 \leq 10$.

The total target fitness of neighbors around $(t)$ is:

$$
T F_{\text {Neighbours }}=\sum_{K=1}^{N N} \frac{D(k) * X_{k}}{N N}
$$

Where $X k$ is the $X_{i}(t)$ neighbor position, the neighbor's index is $\mathrm{k}$, the total no. of $\mathrm{X}_{\mathrm{i}}(\mathrm{t})$ neighbors, and $\mathrm{D}(\mathrm{K})$ is the degree of fitness for each neighbor obtained by:

where,

$$
D(k)=\frac{\partial_{1}(V-\operatorname{Min}(V))}{\operatorname{Max}(V)-\operatorname{Min}(V)}+\partial_{2}
$$

$$
V=\frac{\text { Fitness }\left(X_{J}(t)\right)}{\operatorname{Fitness}\left(X_{i}(t)\right)} \text {, and } 0<\partial_{1}, \partial_{2} \leq 1
$$


All mentioned equations are repeated at every iteration. Assuming $\mathrm{t}$ is iterations number and $\mathrm{n}$ is the agents number, the LFD time.

\section{OBJECTIVE FUNCTION}

The aim of this project is to find more optimal values for PI controllers and SMC setting that control the rotor speed of the BLDC motor. To solve the optimization problem, a target function must be used to create an appropriate search space and find the best PI parameters and SMC setting.

Different error parameters of the system's dynamic response can be used to describe the objective function. In this paper, integrated time absolute error (ITAE) is used as objective function helps us to achieve better results.

The minimum objective function equation that used with LFD algorithm is described as:

$$
J=\min \left(\int_{0}^{T_{\text {simulation }}} t *\left[\left|e_{w}\right|+\left|e_{i}\right|\right] d t\right)
$$

Equation (38) can be used to describe the optimization problem in terms of the objective function: $J$ should be as small as possible. where $\mathrm{T}_{\text {simulation }}$ is the final simulation time. The problem constraints are the parameter limit of the controller; therefore, the parameters of two PI controller are limited or SMC setting in order to help the optimization algorithm to achieve the best parameter as fast time. So, the constrained problem design can be formulated as follows:

for SMC:

For PI controller

$$
\left.\begin{array}{r}
K_{\min } \leq K \leq K_{\max } \\
C_{\min } \leq C \leq C_{\max }
\end{array}\right\}
$$

$$
\left.K_{\text {pmin }} \leq K_{p} \leq K_{\text {pmax }}\right\}
$$

The equation $(39 \& 40)$, which are indicated the limited values of tune PI and SMC which used with LFD algorithm to tune the best parameters of proposed controller. Fig. 5 show the process of tuning the gain values of PI controller and the setting coefficient of SMC with control scheme.

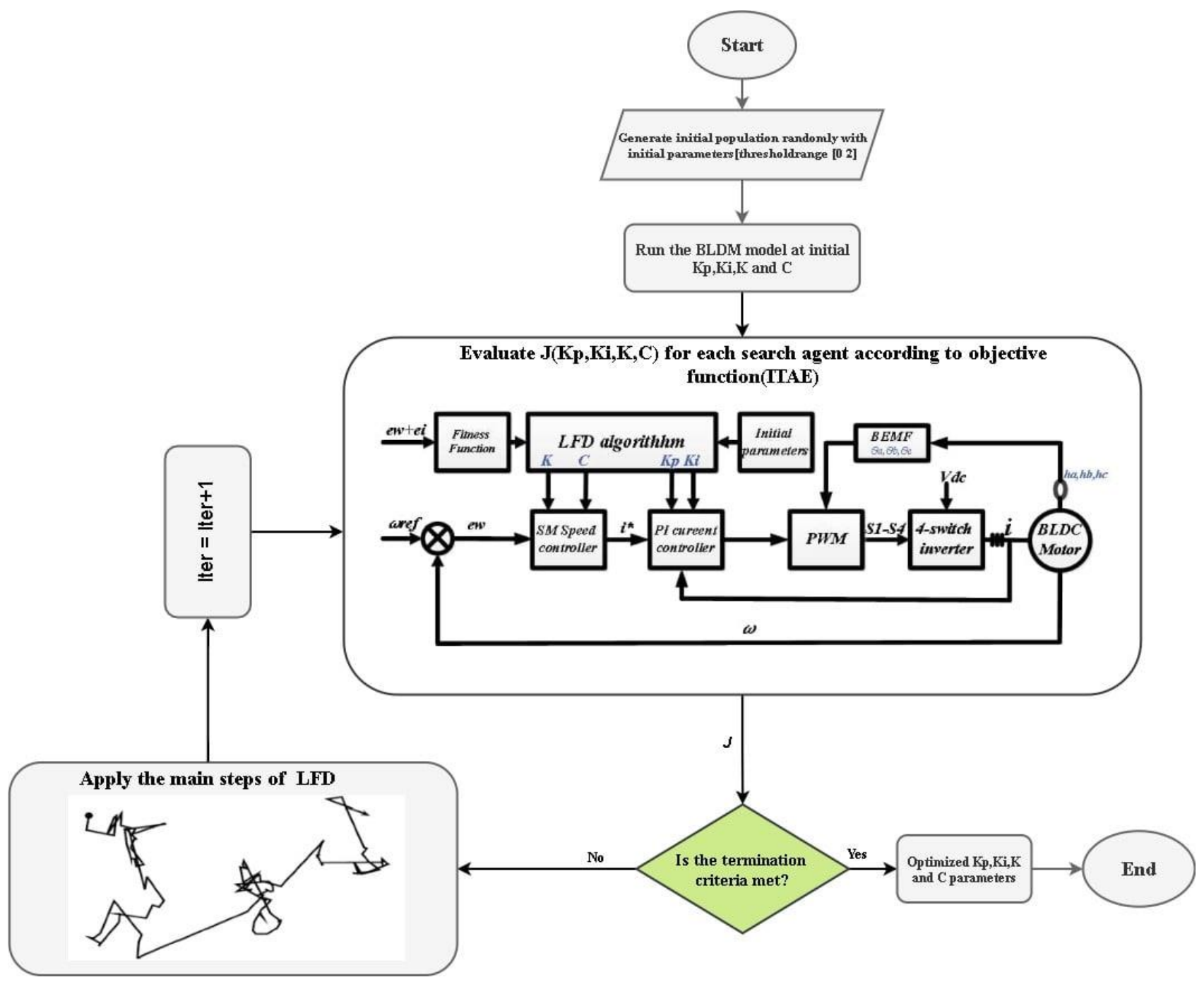

Fig. 5: Flowchart of LFD for tuning the parameters of SMC and PI parameters. 


\section{Simulation RESUltS AND DisCUSSIONS}

The simulation results using Matlab software for proposed optimizing SMC using the LFD algorithm and comparative performance with optimized PI controller and traditional SMC have been presented in this section. Table IV lists the parameters of the BLDC motor model utilized in the simulations. While, Table V depicted the optimal SMC and PI parameters based on LFD technique under same constraints which are (search agent $=10$, maximum iteration=10 and threshold value equal to 1.5 ).

TABLE IV

SPECIFICATION OF BLDM TYPE (LVT57BL-94-001-05).

\begin{tabular}{|c|c|c|}
\hline Parameters & Value & Unit \\
\hline DC voltage & Vdc & $36 \mathrm{~V}$ \\
\hline Rated speed & $\omega$ & $4000 \mathrm{RPM}$ \\
\hline Rated torque & $\mathrm{Te}$ & $0.32 \mathrm{Nm}$ \\
\hline maximum current & $\mathrm{Ia}$ & $16.5 \mathrm{~A}$ \\
\hline Resistance & $\mathrm{R}$ & $0.45 \Omega$ \\
\hline Inductance & $\mathrm{L}$ & $1.4 \mathrm{mH}$ \\
\hline Torque constant & $\mathrm{Kt}$ & $0.063 \mathrm{Nm} / \mathrm{A}$ \\
\hline Moment inertia & $\mathrm{J}$ & $0.0000173 \mathrm{Kg} / \mathrm{m}^{2}$ \\
\hline Number of poles & $\mathrm{p}$ & 4 \\
\hline
\end{tabular}

TABLE V

PARAMETERS OF CONTROLLERS

\begin{tabular}{|c|c|c|c|c|c|c|}
\hline Techniques & $\mathrm{C}$ & $\mathrm{K}$ & \multicolumn{2}{|c|}{$\begin{array}{c}\text { Speed } \\
\text { controller }\end{array}$} & \multicolumn{2}{c|}{$\begin{array}{c}\text { Current } \\
\text { controller }\end{array}$} \\
\cline { 4 - 7 } & & & $\mathrm{Kp}$ & $\mathrm{Ki}$ & $\mathrm{Kp}$ & $\mathrm{Ki}$ \\
\hline $\begin{array}{c}\text { Ziegler-Nic } \\
\text { hols }\end{array}$ & 2000 & 5000 & 8 & 20 & 10 & 0.9 \\
\hline LFD & $\begin{array}{c}4882.7 \\
808\end{array}$ & $\begin{array}{c}4860.1 \\
12\end{array}$ & $\begin{array}{c}2.50 \\
70\end{array}$ & $\begin{array}{c}3.43 \\
05\end{array}$ & $\begin{array}{c}4.9 \\
44\end{array}$ & $\begin{array}{c}3.43 \\
79\end{array}$ \\
\hline
\end{tabular}

The fitness function tracking performance for SMC and PI controller based on LFD is shown in Fig. 6 (a \&b). It obvious from this Figure, the SMC with LFD has minimum fitness value as compared with PI with LFD approach.

To show the robustness of the proposed system and to investigate the TPFSI is emulating the three phase six switch, the simulation results are divided into two scenarios which are dynamic response under rated conditions ( $\mathrm{w}=4000 \mathrm{RPM}$ and load torque $0.32 \mathrm{Nm}$ ) and dynamic response under non-uniform conditions.

\section{Scenario I: dynamic responses of BLDC motor under rated conditions.}

According to Figs. (7 - 12) the optimization sliding mode control has a considerably better reaction than the optimization PI control, and the speed drop when a load is added to the system is significant in the PI control but negligible in the SMC.

Figure (7) shows the comparative dynamic speed response for PI, LFD-PI, SMC, LFD-SMC, it can be seen that, the speed response based on SMC and LFD SMC is better than PI controller and LFD-PI in terms of less steady state error, no overshoot. Also, the chattering is mitigating with LFD-SMC as compared with SMC.

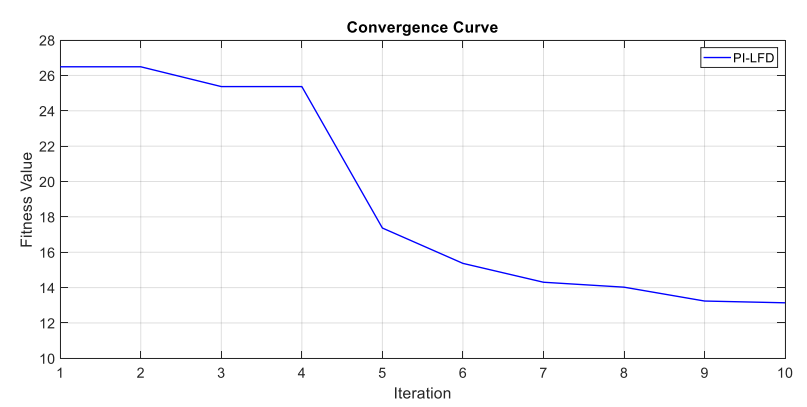

(a)

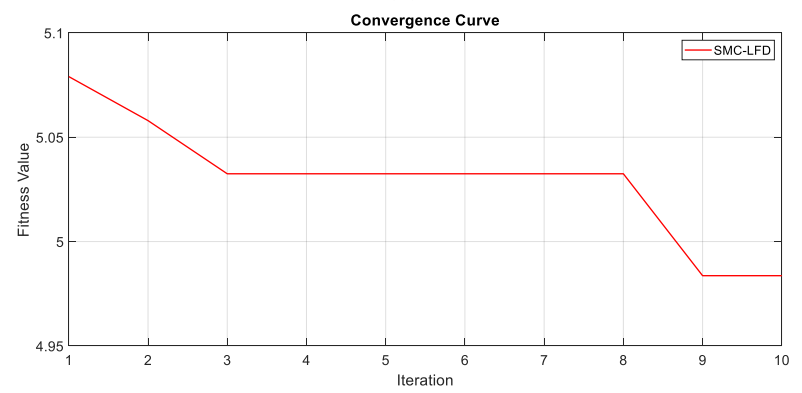

(b)

Fig. 6: Fitness function of (a) PI based on LFD, (b) SMC based on LFD.

Figure (8) depicted the torque response and we notice the SMC and LFD-SMC have notability over PI and optimum PI controller in reducing the overshoot and torque ripple. While, Fig. (9) show the speed error for the four approaches and also, the LFD with SMC is continued as better performance in reducing error and tracking on the zero which implies no error at steady-state region. On other hand, Fig. (10) shows the torque-speed characteristic and we notice from this Fig., the torque-speed characteristic is fast reached the desired value with LFD-SMC without overshoot and very less ripple as compared with PI and SMC techniques.

Finally, Figs. (11 and 12) demonstrated the stator currents and trapezoidal back EMF voltage under rated conditions, it can be seen that the stator current and back EMF voltage has an excellent steady state based on LFD -SMC as compared with other techniques.

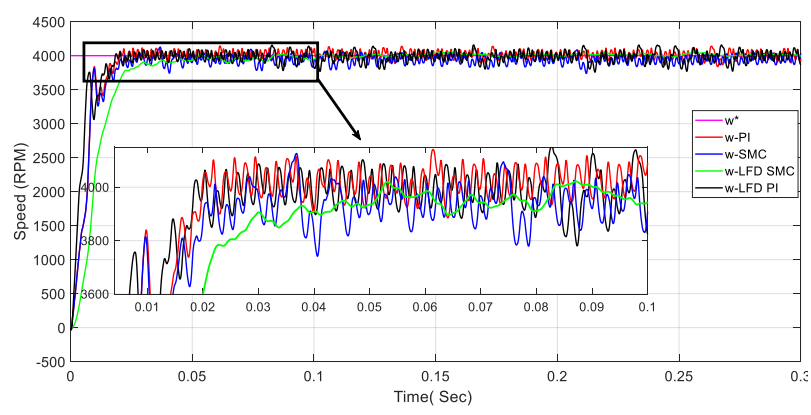

Fig. 7: Speed Response of BLDCM. 


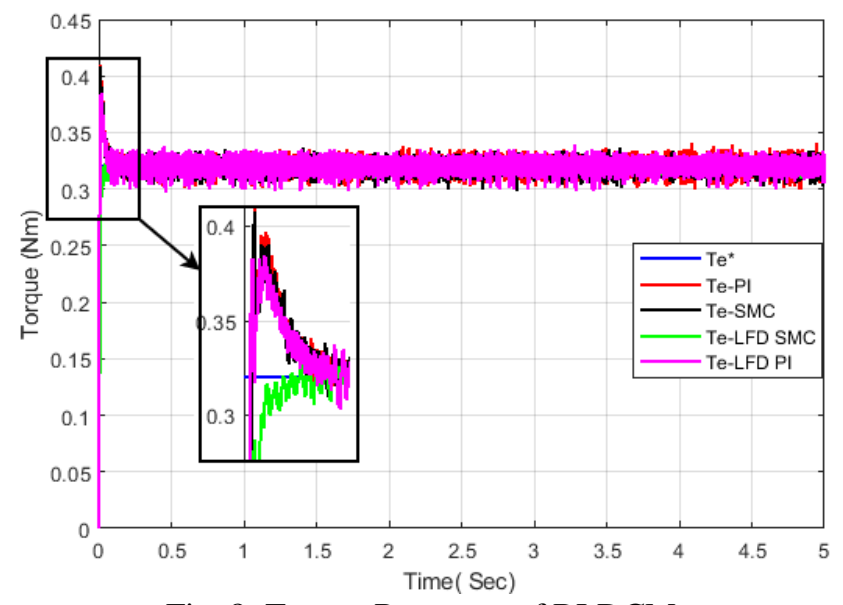

Fig. 8: Torque Response of BLDCM

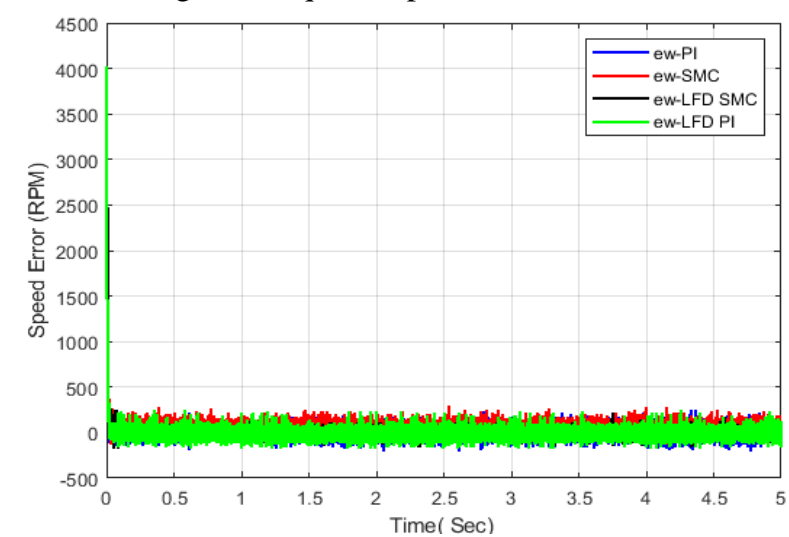

Fig. 9: Speed Error.

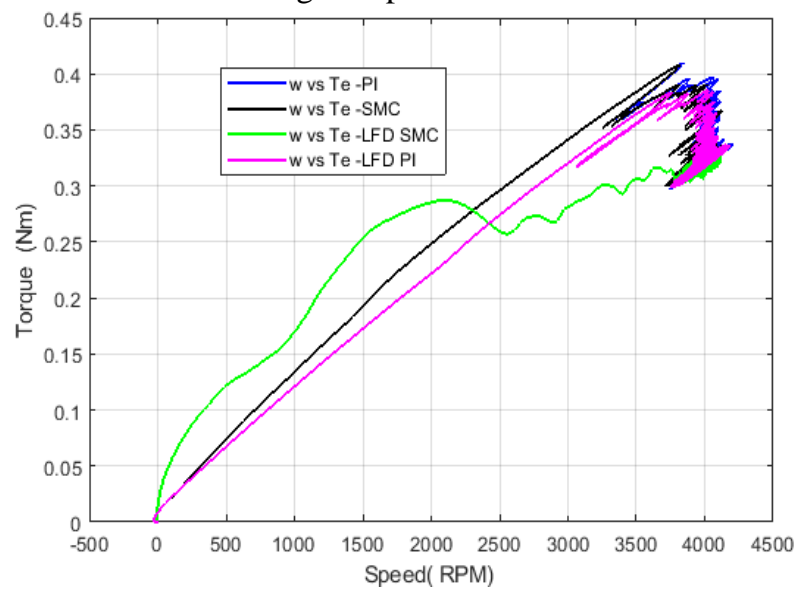

Fig. 10: Torque speed characteristic of BLDCM.
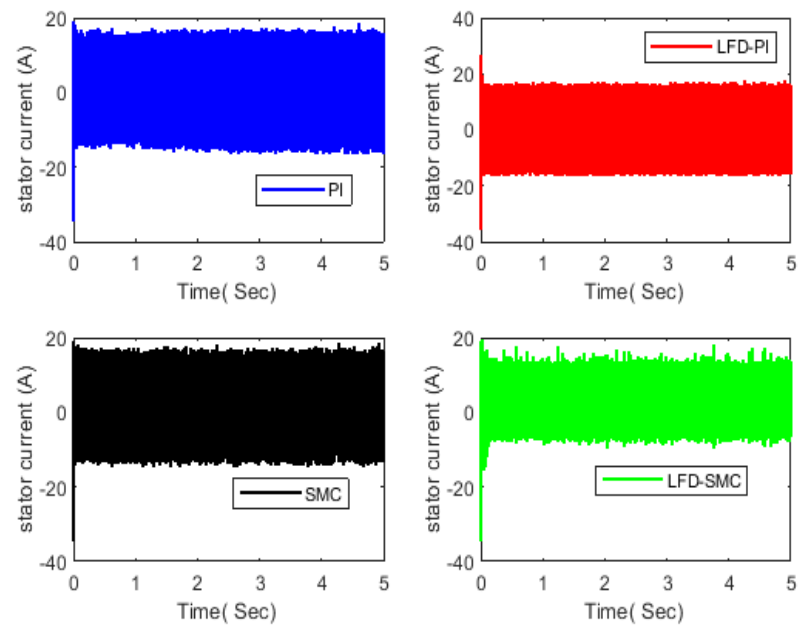

(a)
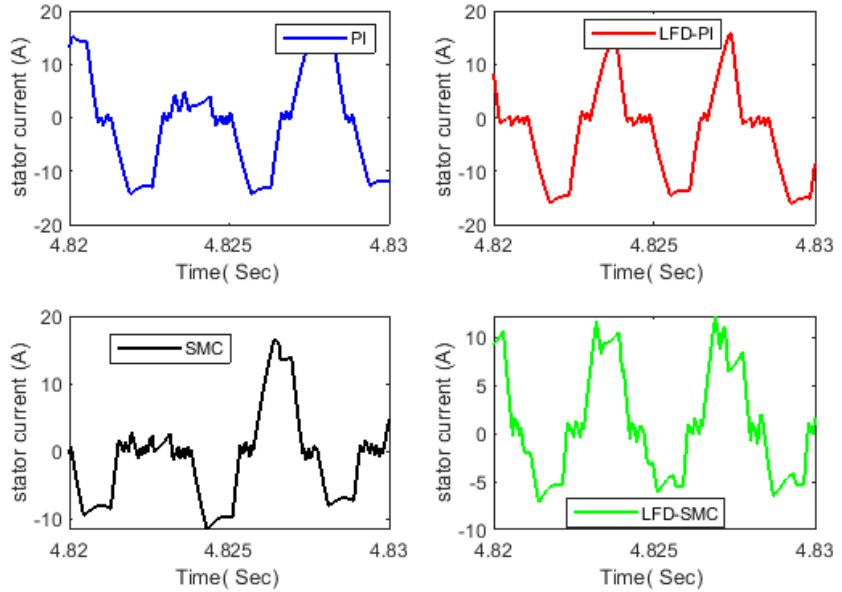

(b)

Fig. 11: (a) Stator currents of BLDCM, (b) Zoomed section of stator currents.
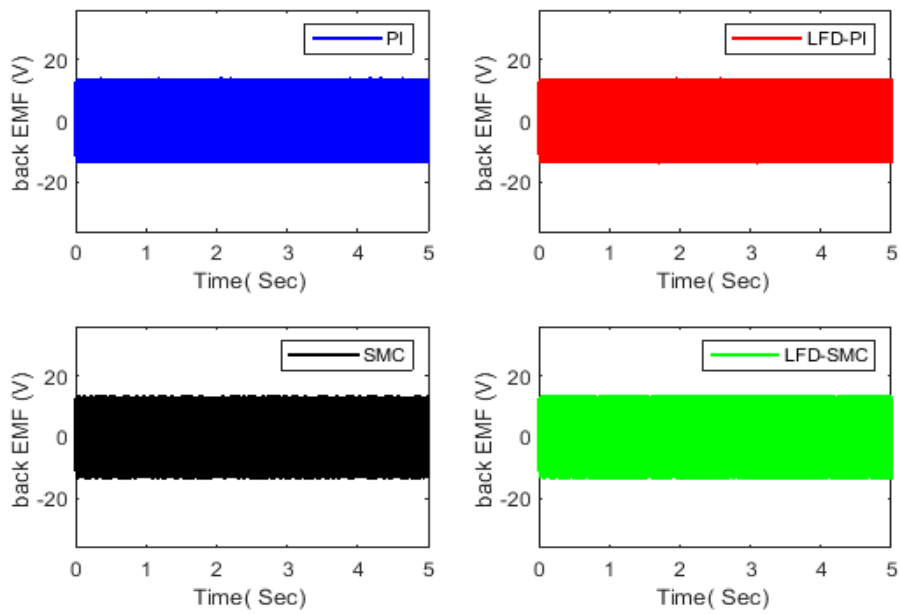

(a)

Fig.12: (a) Back EMF response under rated condition, (b) Zoomed section of Back EMF 

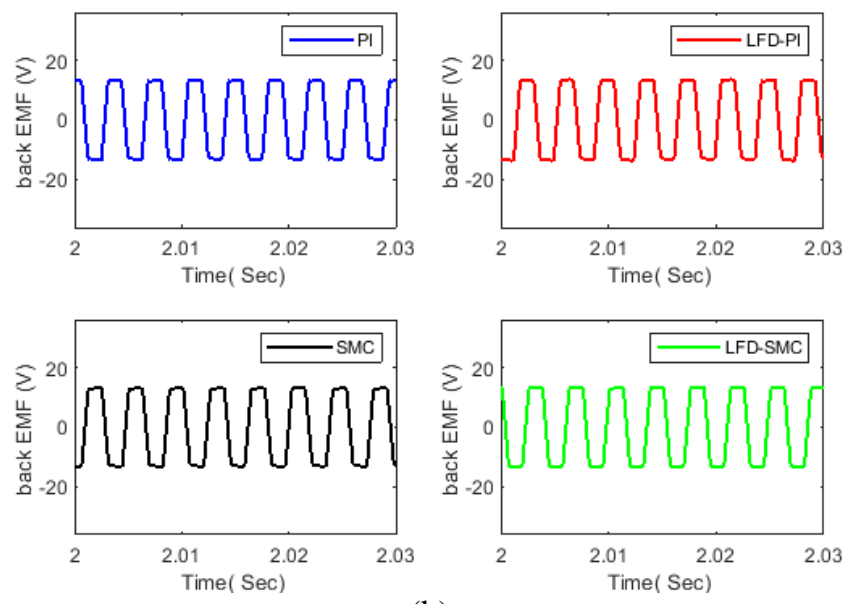

(b)

Fig.12: Continued.

Scenario II: dynamic responses of BLDC motor under Non-uniform conditions

To show the robustness of the proposed control strategy with the LFD algorithm with TPFSI, the proposed system is examined under various speeds and step-change loads between $(0.2 \mathrm{Nm}$ to $0.32 \mathrm{Nm}$ at $\mathrm{t}=1 \mathrm{~s})$.

Figure (13) demonstrated the speed response, it is obvious from this Fig. the actual speed is fast-tracking to desired value under variable speed, and also, the speed response with LFD-SMC has accurate trajectory tracking with no overshoot and very little chattering as compared with traditional SMC.

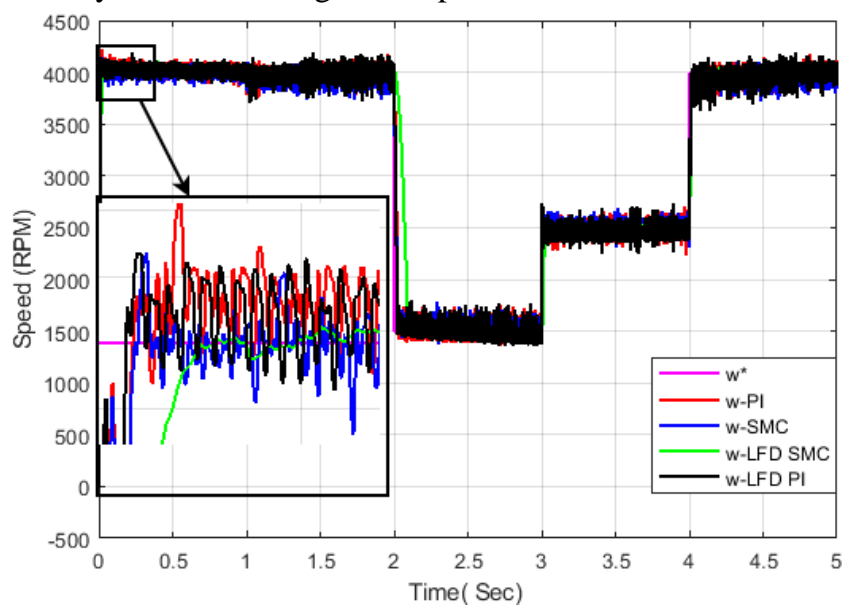

Fig. 13: Speed Response of BLDCM.

The figs (14, 15 and 16) have the same superiority based on LFD-SMC as compared with SMC, PI, and LFD-PI controllers in terms of no steady-state error, less overshoot, and fast-tracking to the desired trajectory. While, Fig. (17 and 18) show the stator current and back EMF voltage are fast change with speed and torque with very short time are reaching to the steady state without overshoot.

In order to provide a fair comparison between related work $[16,21]$ and also the proposed SMC based on the LFD algorithm with PI controller based on LFD that proposed in this paper to investigate the TPFSI is robust, the specification criteria are depicted in Table VI. It can obvious from the results in this table, the LFD-SMC has less rise time and less settling time which implies its fast reach to steady-state and it has a high steady-state with no overshoot and very little ripple.

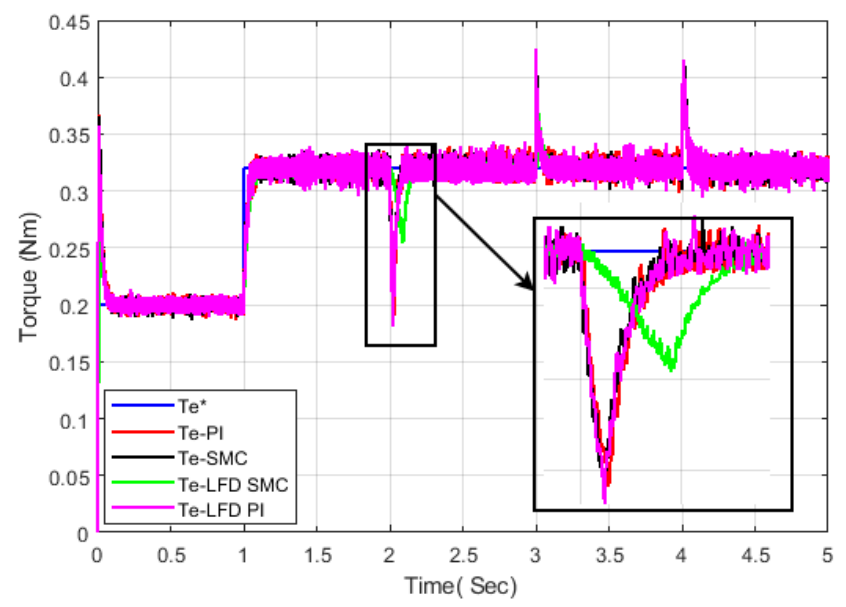

Fig. 14: Torque Response of BLDCM.

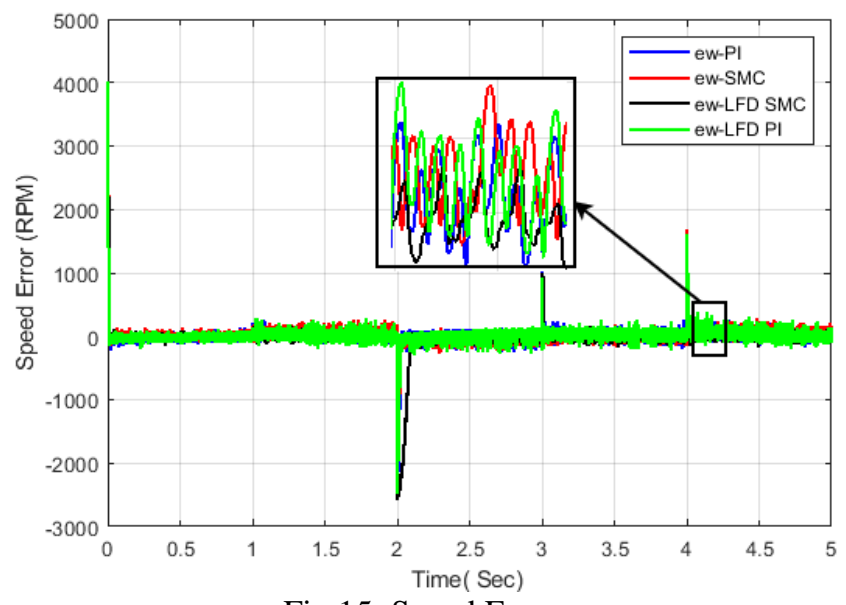

Fig.15: Speed Error.

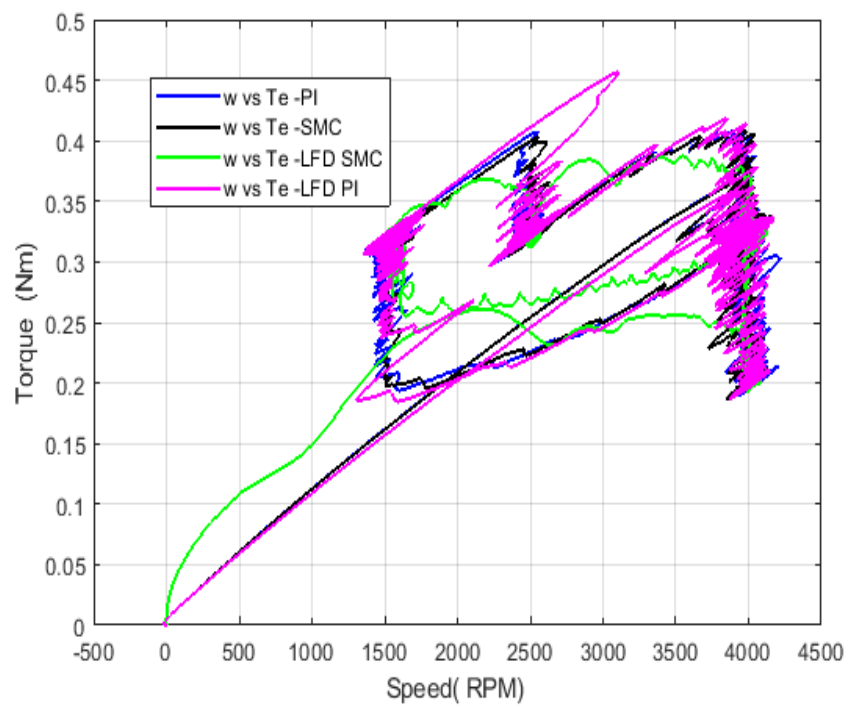

Fig. 16: Torque speed characteristic of BLDCM. 

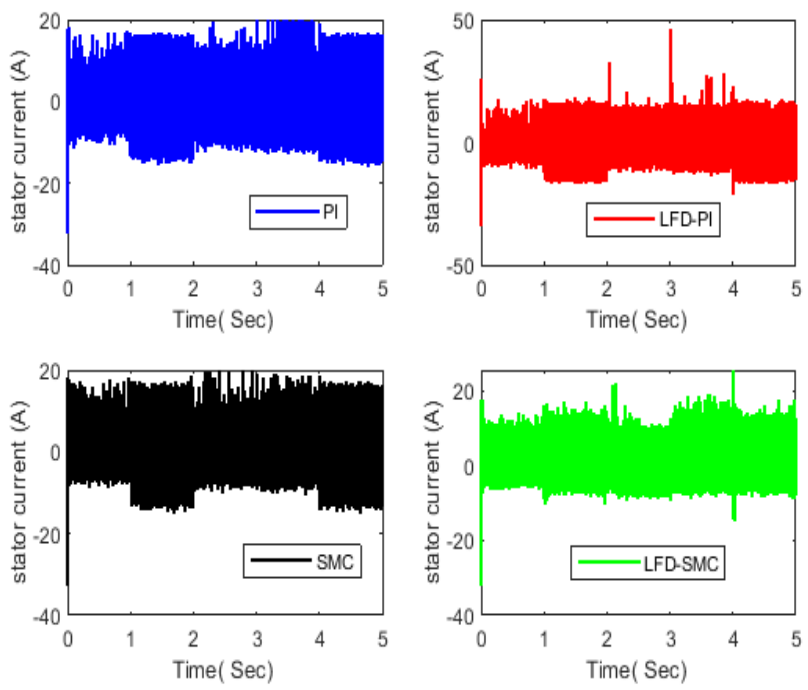

(a)
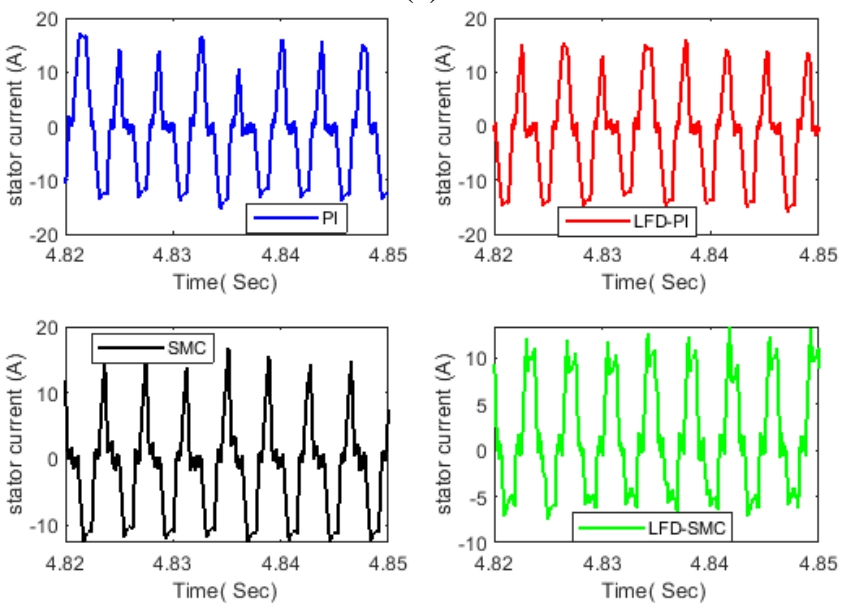

(b)

Fig. 17: (a) Stator currents of BLDCM under non-uniform condition (b) Zoomed section of stator currents.
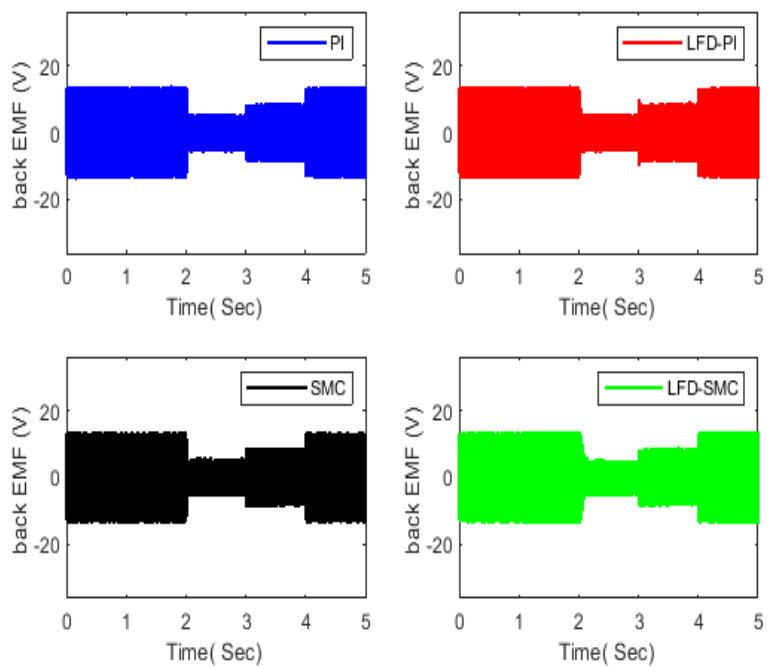

(a)
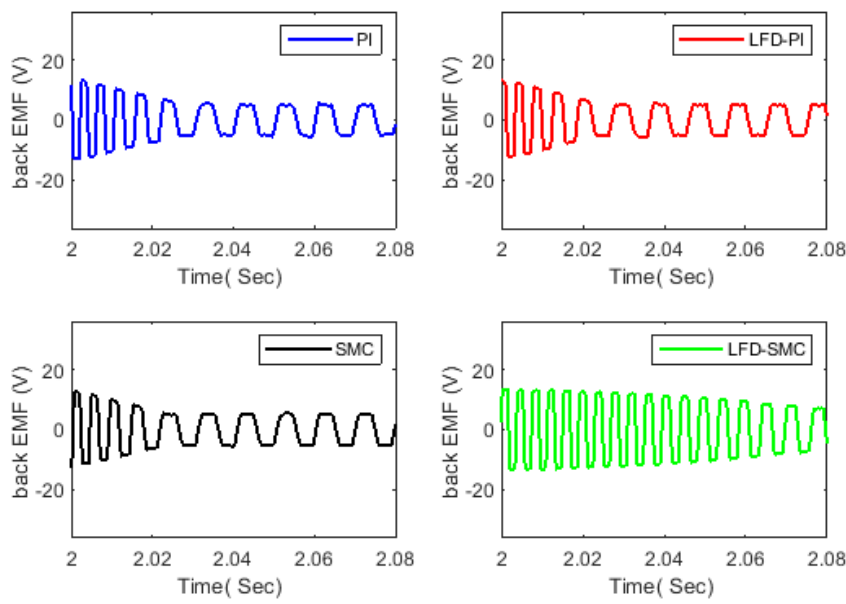

(b)

Fig. 18: (a) Back EMF response under non-uniform condition, (b) Zoomed section of Back EMF.

TABLE VI: PERFORMANCE CRITERIA OF OUTPUT SPEED RESPONSE

\begin{tabular}{|c|c|c|c|c|c|c|}
\hline $\begin{array}{c}\text { Techniqu } \\
\mathrm{e}\end{array}$ & ITAE & ISE & $\begin{array}{c}\text { Oversho } \\
\text { ot } \\
(\mathrm{RPM})\end{array}$ & $\begin{array}{l}\text { Rise } \\
\text { time }\end{array}$ & $\begin{array}{l}\text { Settlin } \\
\text { g time }\end{array}$ & $\begin{array}{c}\text { Rippl } \\
\text { e } \\
\text { (RP } \\
\text { M) }\end{array}$ \\
\hline LFD-PI & 12.6 & - & 92 & $\begin{array}{c}24 \mathrm{~m} \\
\mathrm{~s}\end{array}$ & $29 \mathrm{~ms}$ & \pm 68 \\
\hline $\begin{array}{c}\text { LFD-SM } \\
\mathrm{C} \\
\end{array}$ & $\begin{array}{l}5.457 \\
7 \\
\end{array}$ & - & 0 & $8 \mathrm{~ms}$ & $11 \mathrm{~ms}$ & \pm 4 \\
\hline [16] & - & $\begin{array}{c}502 \\
4 \\
\end{array}$ & 74 & & $15 \mathrm{~ms}$ & \pm 1 \\
\hline [21] & - & - & 3 & $1 \mathrm{~s}$ & $1.3 \mathrm{~s}$ & \pm 8 \\
\hline
\end{tabular}

\section{CONCLUSION}

This manuscript introduces a low-cost BLDC motor drive using a four-switch inverter emulating the objective of the six-switch inverter. The number of inverter power switches is reduced, resulting in cost savings with a low complexity control circuit in real-time implementation. In this study, the LFD algorithm is used to tuning the optimum SMC parameters and compared with the optimum gains of the PI controller to show the supremacy of the SMC approach and to achieve excellent tracking for speed with minimizing speed error of BLDC motor under sudden change conditions. The simulation results demonstrated the robust response of the BLDC motor based on optimum SMC controller under variable speed and load torque as compared with optimization PI and traditional SMC. Also, the optimized SMC based on LFD technique has superiority in reducing the chattering in speed response over traditional SMC. The proposed control with a four-switch inverter is suitable for applications where the load grows as the speed increases.

\section{CONFLICT OF INTEREST}

The authors have no conflict of relevant interest to this article. 


\section{REFERENCES}

[1] Xia, Chang-liang, "Permanent magnet brushless DC motor drives and controls", John Wiley \& Sons, 2012.

[2] Carev, Vadim, et al, "A Multilayer Brushless DC Motor for Heavy Lift Drones", Energies, vol. 14, no. 9, 2021.

[3] Niasar, A. Halvaei, Abolfazl Vahedi, and Hassan Moghbelli, "A novel position sensorless control of a four-switch, brushless DC motor drive without phase shifter", IEEE Transactions on Power Electronics, vol. 23, no. 6, pp. 3079-3087, 2008.

[4] Lee, Byoung-Kuk, Tae-Hyung Kim, and Mehrdad Ehsani. "On the feasibility of four-switch three-phase BLDC motor drives for low cost commercial applications: Topology and control", IEEE Transactions on Power Electronics, vol. 18, no. 1, pp. 164-172, 2003.

[5] Premkumar, K., and B. V. Manikandan, "Fuzzy PID supervised online ANFIS based speed controller for brushless dc motor", Neurocomputing, vol. 157, pp. 76-90, 2015.

[6] Prasad, KM Arun, and Usha Nair, "An intelligent fuzzy sliding mode controller for a BLDC motor", 2017 International Conference on Innovative Mechanisms for Industry Applications (ICIMIA). IEEE, 2017.

[7] Norsahperi, N. M. H., and K. A. Danapalasingam, "An improved optimal integral sliding mode control for uncertain robotic manipulators with reduced tracking error, chattering, and energy consumption", Mechanical Systems and Signal Processing, vol. 142, 2020.

[8] Faulwasser, Timm, et al. "Implementation of nonlinear model predictive path-following control for an industrial robot", IEEE Transactions on Control Systems Technology, vol. 25, no. 4, pp. 1505-1511, 2016.

[9] Zhang, Liyin, et al., "Continuous finite-time control for uncertain robot manipulators with integral sliding mode", IET Control Theory \& Applications, vol. 12, no. 11, pp. 1621-1627, 2018.

[10] Premkumar, K., and B. V. Manikandan, "Speed control of Brushless DC motor using bat algorithm optimized Adaptive Neuro-Fuzzy Inference System", Applied Soft Computing, vol. 32, pp. 403-419, 2015.

[11] Orman, Kamil, "Design of a Memristor-based Chattering Free Sliding Mode Controller and Speed Control of the BLDC Motor", Tehnički vjesnik, vol. 28, no. 3, pp. 754-762, 2021.

[12] Kommula, Bapayya Naidu, and Venkata Reddy Kota, "Direct instantaneous torque control of Brushless DC motor using firefly Algorithm based fractional order PID controller", Journal of King Saud University-Engineering Sciences, vol. 32, no. 2, pp. 133-140, 2020.

[13] Kamal, Md Mustafa, Lini Mathew, and S. Chatterji, "Speed control of brushless DC motor using intelligent controllers", 2014 Students Conference on Engineering and Systems. IEEE, 2014.

[14] Goswami, Rakesh, and Dheeraj Joshi, "Performance review of fuzzy logic based controllers employed in brushless DC motor", Procedia computer science, vol. 132 pp. 623-631, 2018.
[15] Demirtas, Metin, "Off-line tuning of a PI speed controller for a permanent magnet brushless DC motor using DSP", Energy Conversion and Management, vol. 52, no. 1, pp. 264-273, 2011.

[16] Gülbaş, Özge, Yakup Hameş, and Murat Furat, "Comparison of PI and Super-twisting Controller Optimized with SCA and PSO for Speed Control of BLDC Motor", 2020 International Congress on Human-Computer Interaction, Optimization and Robotic Applications (HORA). IEEE, 2020.

[17] Yigit, Tevfik, and Hakan Celik, "Speed controlling of the PEM fuel cell powered BLDC motor with FOPI optimized by MSA", International Journal of Hydrogen Energy, vol. 45, no. 60, pp. 35097-35107, 2020.

[18] Premkumar, K., and B. V. Manikandan, "Bat algorithm optimized fuzzy PD based speed controller for brushless direct current motor", Engineering Science and Technology, an International Journal, vol. 19, no. 2, pp. 818-840, 2016.

[19] Ibrahim, H. E. A., F. N. Hassan, and Anas O. Shomer, "Optimal PID control of a brushless DC motor using PSO and BF techniques", Ain Shams Engineering Journal, vol. 5, no. 2, pp. 391-398, 2014.

[20] Houssein, Essam H., et al., "Lévy flight distribution: A new metaheuristic algorithm for solving engineering optimization problems", Engineering Applications of Artificial Intelligence, vol. 94, 2020.

[21] Shao, Yunbin, et al., "Sliding mode speed control for brushless DC motor based on sliding mode torque observer", 2015 IEEE International Conference on Information and Automation. IEEE, 2015.

[22] Ezzaldean, Mohammed Moanes, and Qusay S. Kadhem, "Design of control system for 4-switch bldc motor based on sliding-mode and hysteresis controllers", IRAQI JOURNAL OF COMPUTERS, COMMUNICATIONS, CONTROL AND SYSTEMS ENGINEERING, vol. 19, no. 1, pp. 42-51, 2019.

[23] Ezzaldean, Mohammed M., and Qusay Sh Kadhem, "New Control System for Four-Switch BLDC Motor Based on Single-Current-Sensor", 2019 International Engineering Conference (IEC). IEEE, 2019. 